\title{
Review Article \\ Postoperative Complications after Thoracic Surgery in the Morbidly Obese Patient
}

\author{
Lebron Cooper \\ University of Miami Miller School of Medicine, Miami, FL 33136, USA \\ Correspondence should be addressed to Lebron Cooper, lcooper@med.miami.edu
}

Received 26 July 2011; Revised 16 October 2011; Accepted 17 November 2011

Academic Editor: Alessia Pedoto

Copyright () 2011 Lebron Cooper. This is an open access article distributed under the Creative Commons Attribution License, which permits unrestricted use, distribution, and reproduction in any medium, provided the original work is properly cited.

Little has been recently published about specific postoperative complications following thoracic surgery in the morbidly obese patient. Greater numbers of patients who are obese, morbidly obese, or supermorbidly obese are undergoing surgical procedures. Postoperative complications after thoracic surgery in these patients that can lead to increased morbidity and mortality, prolonged hospital stay, and increased cost of care are considered. Complications include difficulties with mask ventilation and securing the airway, obstructive sleep apnea with risk of oversedation, pulmonary complications related to reduced total lung capacity, reduced functional residual capacity, and reduced vital capacity, risks of aspiration pneumonitis and ventilator-associated pneumonia, cardiomyopathies, and atrial fibrillation, inadequate diabetes management, positioning injuries, increased risk of venous thrombosis, and pulmonary embolism. The type of thoracic surgical procedure may also pose other problems to consider during the postoperative period. Obese patients undergoing thoracic surgery pose a challenge to those caring for them. Those working with these patients must understand how to recognize, prevent, and manage these postoperative complications.

\section{Introduction}

Little has been recently published about specific postoperative complications following thoracic surgery in the morbidly obese patient. Anesthesia and postoperative management of morbidly obese patients in thoracic surgery are based on experience in these patients undergoing other types of procedures [1]. While approximately $5 \%$ of patients undergoing surgical procedures are considered morbidly obese (BMI > $\left.40 \mathrm{~kg} / \mathrm{m}^{2}\right)$, another $30 \%$ of patients in the US are considered obese $\left(\mathrm{BMI}>30 \mathrm{~kg} / \mathrm{m}^{2}\right)$ [2]. The exact number of these who require thoracic surgery is unknown. However, considering that postoperative complications are a major cause of morbidity, mortality, prolonged hospital stay, and increased cost of care, it is important that those working with these patients during the postoperative period understand how to recognize, prevent, and manage these complications [3].

\section{Airway Complications}

Mask ventilation and intubation may be difficult in the morbidly obese patient secondary to excessive tissue in the posterior pharyngeal wall [4]. A Mallampati score of III or IV and increased neck circumference have been found to be the best predictors of potential difficulty with tracheal intubation [5]. These considerations should be kept in mind when planning extubation following thoracic surgery in the morbidly obese patient, whether using a double-lumen tube or a single-lumen endotracheal tube with a bronchial blocker. The extubation plan should consider the initial ease of mask ventilation, the difficulty of intubation (should reintubation become necessary), and the type of procedure performed. In a comparison between transmediastinal and transthoracic esophagectomy, Bartels et al. found that early extubation (within 6 hours) following transthoracic esophagectomy prolongs ICU length of stay and leads to an increase rate of mortality [6], although the recent trend to extubate immediately after resection in the operating room has been shown to be equally safe. When comparing early extubation in the operating room to late extubation in the ICU, Lanuti et al. found that operative approach did not influence the failure to extubate [7]. Positioning morbidly obese patients in reverse Trendelenburg has been suggested to optimize ventilation and access to the airway should the need for reintubation occur [1]. 


\section{Obstructive Sleep Apnea}

Although most morbidly obese patients have probably not had previous sleep studies to prove the existence of obstructive sleep apnea, many may actually have this disease. The American Society of Anesthesiologists Task Force on Perioperative Management Practice Guidelines for the perioperative management of patients with obstructive sleep apnea warns that judicious use of sedatives and opiates in the perioperative period is indicated in patients with obstructive sleep apnea [8]. It is probably wise to consider judicious use of sedatives and opiates in all morbidly obese patients to prevent oversedation and delayed airway obstruction. Nonsteroidal analgesics may reduce the need for opiates in the postoperative period [9].

\section{Pulmonary Complications}

Morbidly obese patients have reduced total lung capacity, reduced functional residual capacity, and reduced vital capacity [10]. Alveolar arterial oxygenation gradient is increased, and atelectasis has been found to persist for at least 24 hours in morbidly obese patients, whereas it disappeared in the nonobese [11]. Consideration should be given to the increased likelihood of pulmonary complications in these patients postoperatively. Complications related to residual atelectasis may result in desaturation. Pneumonia, bronchospasm, atelectasis, acute respiratory insufficiency, prolonged ventilation, and bronchial infections were found in $33.9 \%$ of patients with mild to moderate COPD undergoing general surgery. Risk factors for increased pulmonary complications were male gender, amount of smoking, duration of surgery over 270 minutes, low FEV1/FVC ratio, and chest or upper abdominal incision [12]. A study of 147 lobectomies, comparing VATS versus open thoracotomy, found that VATS patients, in spite of having more comorbidities, had significantly less postoperative pneumonia, fewer chest tube days, and a shorter hospital length of stay [13].

Ventilator-associated pneumonia can be a life-threatening complication in the course of $8-28 \%$ of mechanically ventilated patients. Mortality rates range between 24 to $50 \%$ and can be as high as $76 \%$, when lung infection is with high-risk pathogens [14]. Several studies have shown that prompt diagnosis and appropriate antimicrobial treatment result in significantly improved outcomes. Important clinical goals are more rapid identification of affected patients and accurate selection of antibiotics [15-17].

Aspiration pneumonitis following regurgitation of gastric contents under general anesthesia, although rare, occurring approximately 1 in every 3,000 general anesthetics, can result in devastating consequences. The mortality rate following aspiration of gastric contents is 1 in 71,000 general anesthetics [18]. Obese patients have typically been considered to have high-volume, low $\mathrm{pH}$ gastric contents that may lead to increased risk of aspiration pneumonitis, although these findings have not been confirmed in more recent studies [19-21].

Pulmonary function can be improved in intubated patients by applying CPAP or PEEP to help avoid atelectasis, improve oxygenation, and reduce $\mathrm{CO}_{2}$ [3]. BiPAP has been shown to significantly reduce pulmonary dysfunction following gastroplasty in obese patients and accelerates reestablishment of preoperative pulmonary function [22]. It would seem likely that this may be beneficial in morbidly obese patients following thoracic surgery as well. Thoracic epidural analgesia has been shown to significantly improve vital capacity in obese patients following midline laparotomy surgery over intravenous opioid analgesia alone and should be considered [23]. Della Rocca et al. reported thoracic epidurals to be superior to IV morphine in terms of analgesia, hospital length of stay, and postoperative complications, such as nausea and vomiting [24]. Paravertebral blocks have been shown to be superior in thoracotomies to thoracic epidural, with fewer complications, such as hypotension and postoperative nausea and vomiting. Although regional techniques of any kind may pose significant challenges in the morbidly obese, consideration should be given to improve postoperative pulmonary function and reduce complications. Of note, contraindications to thoracic epidural placement do not preclude paravertebral blocks as there appears to be a decreased risk of neurological injury [25]. Dexmedetomidine, an alpha 2 agonist with properties that have minimal effects on respiration, may be useful in these patients [26].

\section{Cardiac Complications}

Right ventricular dysfunction can be demonstrated by echocardiography in many obese patients, even if asymptomatic [27]. A great risk of pulmonary and systemic hypertension, related to increased blood volume and higher cardiac output, may exist in morbidly obese patients. Obesity cardiomyopathy with left- and right-heart failure secondary to eccentric right and left ventricular hypertrophy may result if these are present for a long period of time. The risk may be increased in the presence of long-standing obstructive sleep apnea [28].

Atrial fibrillation is a common complication in the obese patient, with risk increasing $4 \%$ per 1-unit increase in BMI [29]. In a study of 2588 patients undergoing noncardiac thoracic surgery, patients who developed atrial fibrillation had increased mean lengths of stay, higher mortality rates, and greater mean hospital charges. Significant variables associated with increased occurrence of atrial fibrillation were male sex, age, history of congestive heart failure, history of arrhythmias, history of peripheral vascular disease, resection of mediastinal tumor, lobectomy, bilobectomy, pneumonectomy, esophagectomy, and intraoperative transfusions [30]. Therapies targeted to reduce the incidence of atrial fibrillation in morbidly obese patients undergoing thoracic surgery seem warranted.

\section{Other Postoperative Complications}

The risk of thromboembolism is thought to be greater in morbidly obese patients [31]. Deep venous thrombosis and skin ulcerations are common in the morbidly obese patient. Varicose veins may occur, and lymphoedema may result [32]. Pulmonary embolism is a real risk for these patients, especially those with decreased mobility [33]. Morbidly obese 
patients have been shown to have a greater incidence of postoperative complications than normal-weight patients undergoing cardiac surgery [34]. Meticulous venous thromboembolism prophylaxis is necessary to decrease the incidence of these complications.

There is a strong correlation between obesity and diabetes mellitus (DM), type 2 , in all ethnic populations. Obesity is attributed to be the cause in more than $80 \%$ of Type 2 DM [32]. Morbidly obese patients have a higher incidence of DM as the degree and duration of obesity, as well as distribution of body fat, increase the risk [35]. Close monitoring of postoperative glucose levels is recommended.

Although no studies have suggested a target glucose level postoperatively in patients who have undergone thoracic surgery, poor intraoperative control of glucose levels in patients undergoing cardiac surgery has been shown to worsen hospital outcomes [36]. However, a recently reported clinical trial of intensive insulin therapy (ACCORD) found a 3- to 4 -fold increase in hypoglycemia which was associated with excess mortality. The risks increased in older patients, coexisting severe comorbidities, the presence of undiagnosed hypoglycemia, and the duration of diabetes and insulin therapy $[37,38]$. It is likely that in morbidly obese patients with coexisting type $2 \mathrm{DM}$ undergoing thoracic surgery the same outcomes may be expected. A recommended target minimum glucose level of $200 \mathrm{mg} / \mathrm{dL}$ has been suggested [35].

The changes in pharmacokinetics and pharmacodynamics caused by obesity provide further challenges in postoperative management of the morbidly obese patient. Organs involved in drug elimination (liver, kidney, etc.) may be affected, and drug administration is difficult, as most recommended doses are based on data obtained from individuals with normal weight. Use of total body weight instead of ideal body weight may result in an inadvertent overdose. Respiratory depression from excessive opioids has been previously discussed. Residual neuromuscular blockade from inappropriate dosing can be lethal. Reversal of neuromuscular blockade with neostigmine has been suggested in all morbidly obese patients, and close monitoring following extubation in the postanesthesia care unit is necessary [39].

Complications following anesthesia for thoracic surgery in morbidly obese patients may also include the same as for other patients, such as nerve injury due to inadequate padding and inappropriate positioning, perioperative myocardial ischemia or infarction, or untoward neurologic sequelae, such as stroke.

\section{Conclusion}

Although little has been published specifically related to morbidly obese patients undergoing thoracic surgery, the risk of postoperative complications is high, which can result in increased morbidity and mortality, increased length of stay, and increased costs of care. Anesthesia providers must be aware of these complications to prevent and manage these patients in the postoperative period. Clinical outcome studies specifically related to the morbidly obese patients are still lacking.

\section{References}

[1] J. Lohser, V. Kulkarni, and J. B. Brodsky, "Anesthesia for thoracic surgery in morbidly obese patients," Current Opinion in Anaesthesiology, vol. 20, no. 1, pp. 10-14, 2007.

[2] M. L. Baskin, J. Ard, F. Franklin, and D. B. Allison, "National prevalence of obesity: prevalence of obesity in the United States," Obesity Reviews, vol. 6, no. 1, pp. 5-7, 2005.

[3] A. Rudra and D. Sudipta, "Postoperative pulmonary complications," Indian Journal of Anaesthesia, vol. 50, no. 2, pp. 89-98, 2006.

[4] L. Busetto, G. Enzi, E. M. Inelmen et al., "Obstructive sleep apnea syndrome in morbid obesity: effects of intragastric balloon," Chest, vol. 128, no. 2, pp. 618-623, 2005.

[5] J. B. Brodsky, H. J. M. Lemmens, J. G. Brock-Utne, M. Vierra, and L. J. Saidman, "Morbid obesity and tracheal intubation," Anesthesia and Analgesia, vol. 94, no. 3, pp. 732-736, 2002.

[6] H. Bartels, H. J. Stein, and J. R. Siewert, "Early extubation vs. late extubation after esophagus resection: a randomized, prospective study," Langenbecks Archiv für Chirurgie, vol. 115, pp. 1074-1076, 1998.

[7] M. Lanuti, P. E. de Delva, A. Maher et al., "Feasibility and outcomes of an early extubation policy after esophagectomy," Annals of Thoracic Surgery, vol. 82, no. 6, pp. 2037-2041, 2006.

[8] J. B. Gross, K. L. Bachenberg, J. L. Benumof et al., "Practice guidelines for the perioperative management of patients with obstructive sleep apnea: a report by the American Society of Anesthesiologists Task Force on Perioperative Management of patients with obstructive sleep apnea," Anesthesiology, vol. 104, pp. 1081-1093, 2006.

[9] P. Rock and A. Passannante, "Preoperative assessment: pulmonary," Anesthesiology Clinics of North America, vol. 22, no. 1, pp. 77-91, 2004.

[10] P. S. Pasulka, B. R. Bistrian, P. N. Benotti, and G. L. Blackburn, "The risks of surgery in obese patients," Annals of Internal Medicine, vol. 104, no. 4, pp. 540-546, 1986.

[11] A.-S. Eichenberger, S. Proietti, S. Wicky et al., "Morbid obesity and postoperative pulmonary atelectasis: an underestimated problem," Anesthesia and Analgesia, vol. 95, no. 6, pp. 17881792, 2002.

[12] R. De Albuquerque Medeiros, S. M. Faresin, and J. R. Jardim, "Postoperative lung complications and mortality in patients with mild-to-moderate COPD undergoing elective general surgery," Archivos de Bronconeumologia, vol. 37, no. 5, pp. 227234, 2001.

[13] B. A. Whitson, R. S. Andrade, A. Boettcher et al., "Videoassisted thoracoscopic surgery is more favorable than thoracotomy for resection of clinical stage I non-small cell lung cancer," Annals of Thoracic Surgery, vol. 83, no. 6, pp. 1965-1970, 2007.

[14] J. Chastre and J. Y. Fagon, "Ventilator-associated pneumonia," American Journal of Respiratory and Critical Care Medicine, vol. 165, no. 7, pp. 867-903, 2002.

[15] A. Torres, R. Aznar, J. M. Gatell et al., "Incidence, risk, and prognosis factors of nosocomial pneumonia in mechanically ventilated patients," American Review of Respiratory Disease, vol. 142, no. 3, pp. 523-528, 1990.

[16] J. Rello, M. Gallego, D. Mariscal, R. Sonora, and J. Valles, "The value of routine microbial investigation in ventilatorassociated pneumonia," American Journal of Respiratory and Critical Care Medicine, vol. 156, pp. 196-200, 1997. 
[17] M. H. Kollef, G. Sherman, S. Ward, and V. J. Fraser, "Inadequate antimicrobial treatment of infections: a risk factor for hospital mortality among critically III patients," Chest, vol. 115, no. 2, pp. 462-474, 1999.

[18] M. A. Warner, M. E. Warner, and J. G. Weber, "Clinical significance of pulmonary aspiration during the perioperative period," Anesthesiology, vol. 78, no. 1, pp. 56-62, 1993.

[19] R. W. Vaughan, S. Bauer, and L. Wise, "Volume of $\mathrm{pH}$ of gastric juice in obese patients," Anesthesiology, vol. 43, no. 6, pp. 686$689,1975$.

[20] R. L. Harter, W. B. Kelly, M. G. Kramer, C. E. Perez, and R. R. Dzwonczyk, "A comparison of the volume and $\mathrm{pH}$ of gastric contents of obese and lean surgical patients," Anesthesia and Analgesia, vol. 86, no. 1, pp. 147-152, 1998.

[21] P. Juvin, G. Fèvre, M. Merouche, T. Vallot, and J.-M. Desmonts, "Gastric residue is not more copious in obese patients," Anesthesia and Analgesia, vol. 93, no. 6, pp. 1621-1622, 2001.

[22] J. L. Joris, T. M. Sottiaux, J. D. Chiche, C. J. Desaive, and M. L. Lamy, "Effect of bi-level positive airway pressure (BiPAP) nasal ventilation on the postoperative pulmonary restrictive syndrome in obese patients undergoing gastroplasty," Chest, vol. 111, no. 3, pp. 665-670, 1997.

[23] B. S. von Ungern-Sternberg, A. Regli, A. Reber, and M. C. Schneider, "Effect of obesity and thoracic epidural analgesia on perioperative spirometry," British Journal of Anaesthesia, vol. 94, no. 1, pp. 121-127, 2005.

[24] G. Della Rocca, C. Coccia, L. Pompei et al., "Post-thoracotomy analgesia: epidural vs intravenous morphine continuous infusion," Minerva Anestesiologica, vol. 68, no. 9, pp. 681-693, 2002.

[25] D. J. Daly and P. S. Myles, "Update on the role of paravertebral blocks for thoracic surgery: are they worth it?" Current Opinion in Anaesthesiology, vol. 22, no. 1, pp. 38-43, 2009.

[26] R. E. Hofer, J. Sprung, M. G. Sarr, and D. J. Wedel, "Anesthesia for a patient with morbid obesity using dexmedetomidine without narcotics," Canadian Journal of Anesthesia, vol. 52, no. 2, pp. 176-180, 2005.

[27] C. Y. Wong, T. O'Moore-Sullivan, R. Leano, C. Hukins, C. Jenkins, and T. H. Marwick, "Association of subclinical right ventricular dysfunction with obesity," Journal of the American College of Cardiology, vol. 47, no. 3, pp. 611-616, 2006.

[28] J. Sidana, W. S. Aronow, G. Ravipati et al., "Prevalence of moderate or severe left ventricular diastolic dysfunction in obese persons with obstructive sleep apnea," Cardiology, vol. 104, no. 2, pp. 107-109, 2005.

[29] T. J. Wang, H. Parise, D. Levy et al., "Obesity and the risk of new-onset atrial fibrillation," Journal of the American Medical Association, vol. 292, no. 20, pp. 2471-2477, 2004.

[30] A. A. Vaporciyan, A. M. Correa, D. C. Rice et al., "Risk factors associated with atrial fibrillation after noncardiac thoracic surgery: analysis of 2588 patients," Journal of Thoracic and Cardiovascular Surgery, vol. 127, no. 3, pp. 779-786, 2004.

[31] S. Flier and J. T. A. Knape, "How to inform a morbidly obese patient on the specific risk to develop postoperative pulmonary complications using evidence-based methodology," European Journal of Anaesthesiology, vol. 23, no. 2, pp. 154-159, 2006.

[32] I. D. Caterson, V. Hubbard, G. A. Bray et al., "Obesity, a worldwide epidemic related to heart disease and stroke. Group III: worldwide comorbidities of obesity," Circulation, vol. 110, no. 18, pp. e476-e483, 2004.
[33] World Health Organization, "Obesity: preventing and managing the global epidemic," Report of a World Health Organization Consultation 256, World Health Organization, Geneva, Switzerland, 2000.

[34] C. H. Wigfield, J. D. Lindsey, A. Muñoz, P. S. Chopra, N. M. Edwards, and R. B. Love, "Is extreme obesity a risk factor for cardiac surgery? An analysis of patients with a BMI $\geq 40$," European Journal of Cardio-thoracic Surgery, vol. 29, no. 4, pp. 434-440, 2006.

[35] J. M. Chan, E. B. Rimm, G. A. Colditz, M. J. Stampfer, and W. C. Willett, "Obesity, fat distribution, and weight gain as risk factors for clinical diabetes in men," Diabetes Care, vol. 17, no. 9, pp. 961-969, 1994.

[36] A. Ouattara, P. Lecomte, Y. Le Manach et al., "Poor intraoperative blood glucose control is associated with a worsened hospital outcome after cardiac surgery in diabetic patients," Anesthesiology, vol. 103, no. 4, pp. 687-694, 2005.

[37] K. K. Ray, S. R. K. Seshasai, S. Wijesuriya et al., "Effect of intensive control of glucose on cardiovascular outcomes and death in patients with diabetes mellitus: a meta-analysis of randomised controlled trials," The Lancet, vol. 373, no. 9677, pp. 1765-1772, 2009.

[38] T. N. Kelly, L. A. Bazzano, V. A. Fonseca, T. K. Thethi, K. Reynolds, and J. He, "Systematic review: glucose control and cardiovascular disease in type 2 diabetes," Annals of Internal Medicine, vol. 151, no. 6, pp. 394-403, 2009.

[39] L. E. C. De Baerdemaeker, E. P. Mortier, and M. M. R. Struys, "Pharmacokinetics in obese patients," Continuing Education in Anaesthesia, Critical Care and Pain, vol. 4, no. 5, pp. 152-155, 2004. 


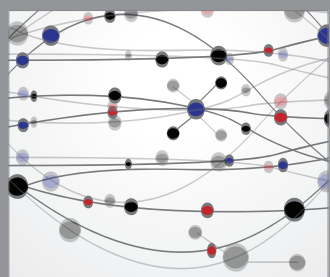

The Scientific World Journal
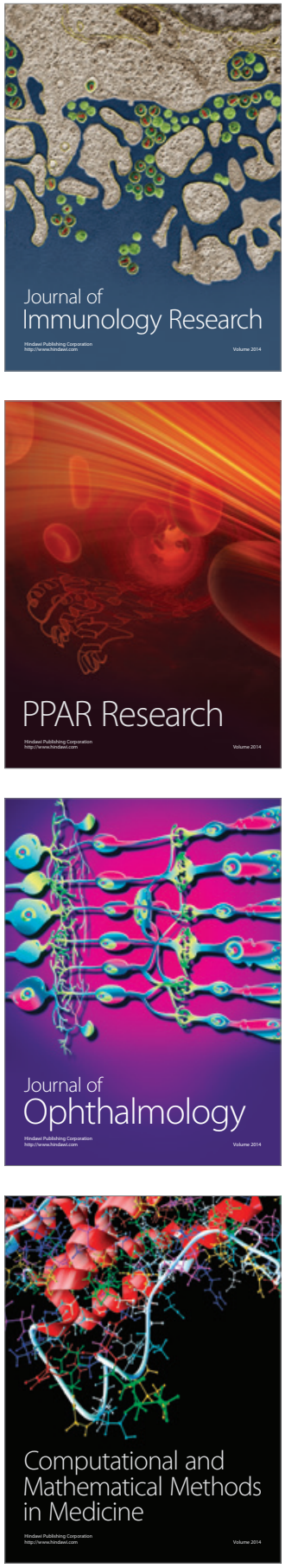

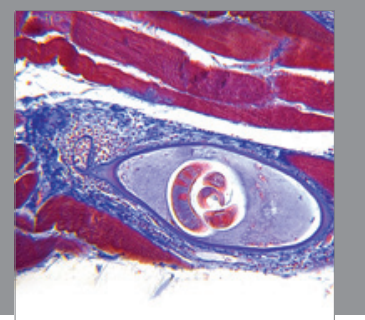

Gastroenterology

Research and Practice
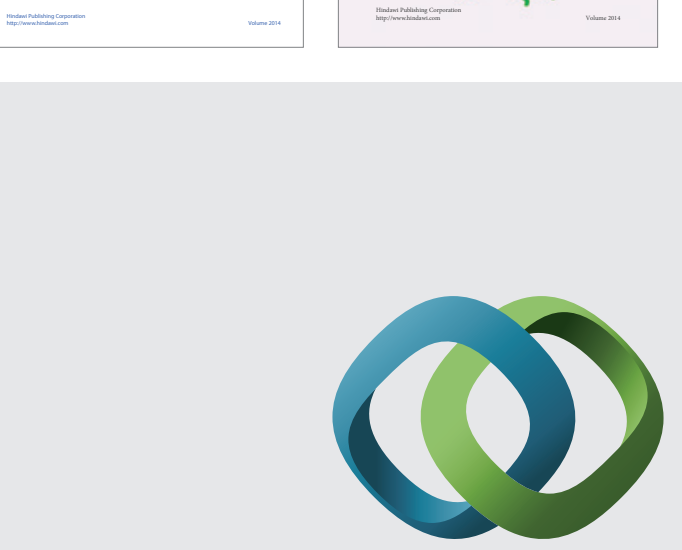

\section{Hindawi}

Submit your manuscripts at

http://www.hindawi.com
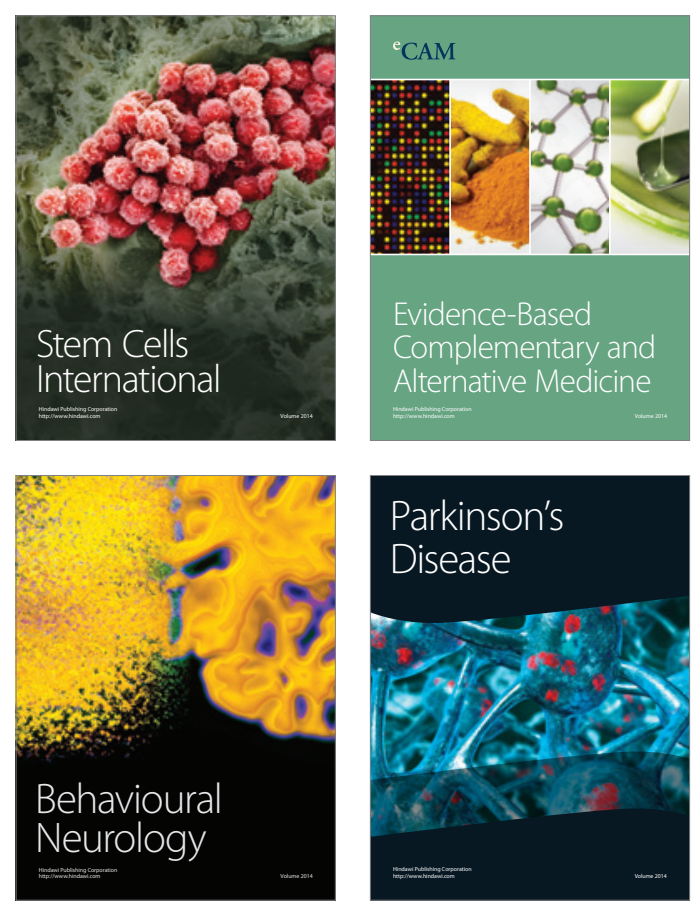

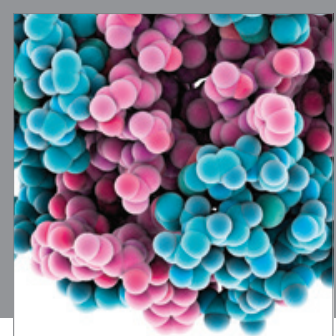

Journal of
Diabetes Research

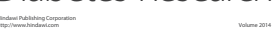

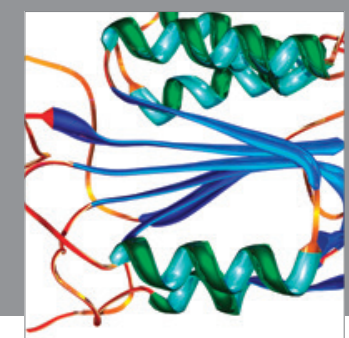

Disease Markers
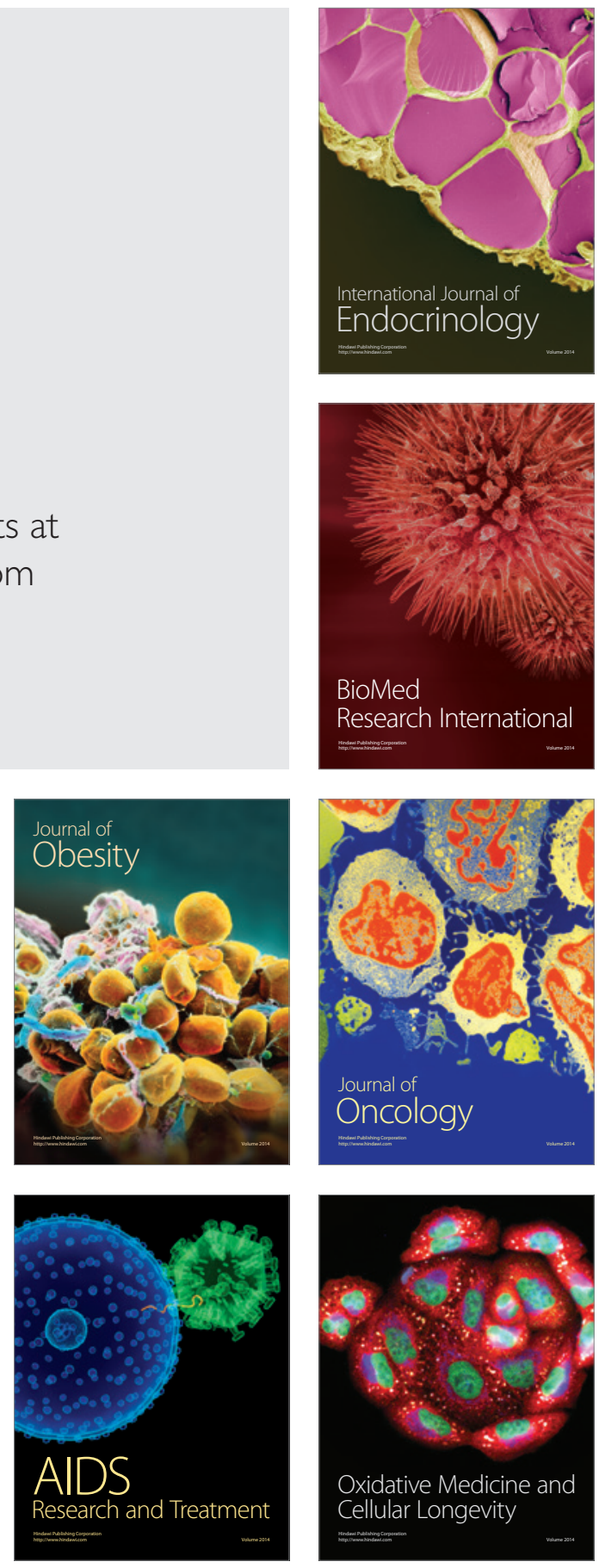